\title{
DETERMINATION OF PARACETAMOL IN COMMERCIAL SUPPOSITORIES USING DIFFERENTIAL SCANNING CALORIMETRY
}

\author{
EDYTA LEYK, SEBASTIAN KOMAR and MAREK WESOŁOWSKI* \\ Department of Analytical Chemistry, Medical University of Gdansk, \\ Gen. J. Hallera 107, 80-416 Gdańsk, Poland
}

\begin{abstract}
Paracetamol, also known as acetaminophen, has been commonly used as a major active pharmaceutical ingredient in numerous analgesics for over 30 years. This means that specific and reliable methods are crucial for quality control of its formulations. The purpose of this work was to show to what extent differential scanning calorimetry (DSC) can be useful for the determination of paracetamol in formulations intended for rectal use. Suppositories commonly available in Polish pharmacies were chosen for the study. In order to assess the impact of various suppository bases on active ingredient determination in the formulations analyzed, the selection was made from various producers and with varying doses of paracetamol. DSC scans were taken on a heat-flux instrument with a liquid nitrogen cooling system. To achieve the aim of this study, a well-defined endothermic DSC peak was used, assigned to the melting-point of paracetamol at $168.64^{\circ} \mathrm{C}$ with the heat of transition of $183.99 \mathrm{~J} / \mathrm{g}$. A multiple standard addition method was chosen for the calibration. Except for one formulation containing $50 \mathrm{mg}$ of paracetamol, the relative standard deviation for all the DSC determinations varied over the range of 0.27 to $2.64 \%$, while the relative error varied between 0.24 and $12.50 \%$. The study demonstrated that DSC could successfully be employed as a simple, specific and reliable method for the determination of paracetamol in rectal preparations based on the measurement of its heat of fusion. The results are consistent with the data obtained using UV spectrophotometry (pharmacopoeial method) as reference.
\end{abstract}

Keywords: paracetamol, DSC determination, multiple standard addition method, commercial suppositories

Paracetamol (N-(4-hydroxyphenyl) acetamide, acetaminophen, panadol) is an important drug that demonstrates antipyretic and analgesic action. Its mode of action is based on the prevention of prostaglandin synthesis largely through the inhibition of the enzyme cyclooxygenase $(1,2)$. The analgesic efficacy of paracetamol is equivalent to that of aspirin but in therapeutic doses, it has only weak anti-inflammatory effects. Hence, paracetamol is effective in mild to moderate pain such as that of headache or dysmenorrhoea. It is also useful in patients who should avoid aspirin due to gastric intolerance, bleeding tendency or allergy, or because they are below the age of 12 .

For medical purposes, paracetamol is available in the form of tablets, capsules, suppositories, liquid suspensions and in intravenous and intramuscular formulations $(3,4)$. The majority of these formulations are used per os because paracetamol is well tolerated by the stomach (2). Regardless of this, heavy, long-term, daily use of this drug results in adverse effects such as chronic renal disease, while acute paracetamol overdose (more than $150 \mathrm{mg} / \mathrm{kg}$ body-weight) can result in severe hepatocellular damage and renal tubular necrosis (1). For this reason, suppositories are the safest and most effective formulations, particularly for children. These are a solid dosage form designed to be inserted into the rectum (rectal suppository), vagina (vaginal suppository) or urethra (urethral suppository) $(3,4)$. Once in the human body, suppositories dissolve or melt and exert a local or systemic effect.

According to the best practices in pharmaceutical technology, both active pharmaceutical ingredients and excipients are used to formulate a safe, effective and stable solid dosage form intended for human use (5). Furthermore, many technological processes are used in the manufacture of various dosage forms, including milling, melting, mixing, granulation, kneading, spray-drying, and lyophilization. Because these processes are likely to change the physicochemical properties of both the active ingredients and excipients, they must be controlled using advanced analytical tools. A screening of the

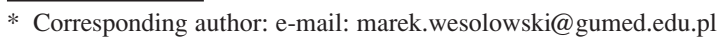


literature shows that thermal methods of analysis such as differential scanning calorimetry (DSC), differential thermal analysis (DTA) and thermogravimetry (TG) have been successfully used to this end (6-8). Application of these methods attracts special attention because the processes used in the manufacture of drug formulations may result in interactions between active ingredients and excipients (9$11)$, the formation of eutectics $(12,13)$, inclusion complexes (14) and co-crystals $(15,16)$, and the disordering of crystal lattice $(17,18)$ and polymorphic transformations (19).

Pharmaceutical legislation obliges national agencies for medicines and medical devices to check pharmaceutical products available on the pharmaceutical market with the established quality requirements $(3,4,20)$. These cover, among others, qualitative and quantitative analysis of drugs in their formulations and biological samples, which is the most challenging issue to overcome owing to the specific character of drugs and the diversity of dosage forms (20-23). Drug analysis also requires a sound knowledge of the technology of drug formulation and the principles of drug quantitation using advanced analytical techniques. In this context, for the analysis of paracetamol in its formulations and biological samples, several different techniques have been used, with spectroscopic $(24,25)$, electroanalytical $(24$, $26,27)$ and chromatographic (24) being the most common.

Taking all the above into consideration, the aim of this study was to show to what extent differential scanning calorimetry (DSC), which is a pharmacopoeial method (4), could be used for the quantitation of paracetamol in suppositories without isolation of active ingredient from the drug formulation. Owing to their complex chemical composition, suppositories are unsuited to quantitative analysis and there is still a paucity of information in the literature about simple, specific and reliable analytical procedures for quantitation of paracetamol in this dosage form. This is an important challenge since DSC has hitherto been used rather for quantitation of drugs in their dosage forms (28). As a result of the study, satisfactory data can only be obtained for formulations in which the drug has a characteristic, well-shaped endothermic DSC peak due to phase transformation, and the excipients remain inert during the enthalpy change and do not interfere with the area of this peak.

\section{EXPERIMENTAL}

\section{Materials}

The analysis consisted of a total number of nineteen suppositories commercially available in pharmacies in Poland. These were as follows (manufacturers given in parentheses): Benuron $125 \mathrm{mg}, 250 \mathrm{mg}$, $500 \mathrm{mg}$, and $1000 \mathrm{mg}$ (Bene-Arzneimittel, München, Germany); Calpol $80 \mathrm{mg}$ and $125 \mathrm{mg}$; Codipar $250 \mathrm{mg}$ and $500 \mathrm{mg}$ (GSK Pharmaceuticals, Poznan, Poland); Efferalgan $80 \mathrm{mg}, 150 \mathrm{mg}$, and $300 \mathrm{mg}$ (Bristol-Myers Squibb, Agen, France); Paracetamol $50 \mathrm{mg}, 125 \mathrm{mg}, 250 \mathrm{mg}$, and $500 \mathrm{mg}$ (Farmina, Krakow, Poland); and Paracetamol $80 \mathrm{mg}, 125 \mathrm{mg}$, $250 \mathrm{mg}$, and $500 \mathrm{mg}$ (Hasco-Lek, Wrocław, Poland).

Paracetamol polymorphic form I (Lot: 6088904V992) was obtained from Polfa (Pabianice, Poland). Its melting point $\left(\mathrm{T}_{\mathrm{on}}=168.64^{\circ} \mathrm{C}\right)$ determined using a DSC instrument confirms the high purity of paracetamol used in this study. The melting point is consistent with pharmacopeial value $168-170^{\circ} \mathrm{C}$ (4) and that for paracetamol used as a standard substance $-169.4^{\circ} \mathrm{C}$ (29). The melting enthalpy $(183.99 \mathrm{~J} / \mathrm{g})$ is also consistent with literature value $(182.58 \pm 7.27 \mathrm{~J} / \mathrm{g})(30)$. Estram H15 and Witepsol S58 were received from Farmina (Krakow, Poland) and Hasco-Lek (Wroclaw, Poland), respectively. All substances used in this study were of pharmacopoeial purity and were used as received.

\section{Methods}

The mean formulation mass was determined based on the combined mass of 10 suppositories. These were crushed and homogenized. When

Table 1. Quantities of paracetamol added as the standard drug to the commercial suppositories.

\begin{tabular}{|c|c|c|c|c|}
\hline \multicolumn{2}{|c|}{ Quantity of paracetamol added to melted drug formulation (mg/g of suppository) } \\
\hline I addition & 25 & 50 & 150 & 200 \\
\hline II addition & 50 & 100 & 250 & 300 \\
\hline III addition & 75 & 150 & 250 and 300 & 500 \\
\hline $\begin{array}{c}\text { Declared dose of paracetamol in } \\
\text { drug formulation (mg/suppository) }\end{array}$ & 50 and 80 & 125 and 150 & 200 \\
\hline
\end{tabular}




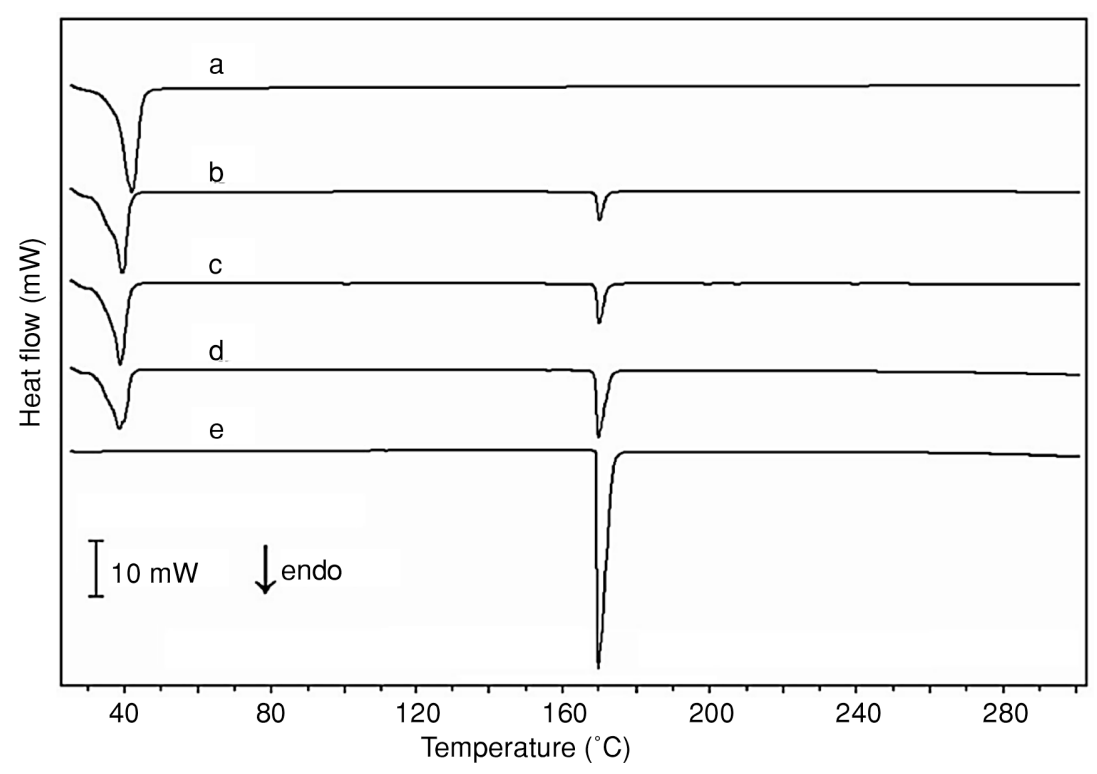

Figure 1. DSC scans for: (a) suppository base Estram H15, (e) paracetamol, and rectal formulations manufactured by Farmina containing the dose of drug: (b) $125 \mathrm{mg}$, (c) $250 \mathrm{mg}$, and (d) $500 \mathrm{mg}$

preparing samples for analysis using the multiple standard addition method, the homogenized suppository mixture was placed in an evaporating dish, melted at $55^{\circ} \mathrm{C}$ on a water bath and then appropriate quantities of paracetamol (as shown in Table 1) were added to the melt. After mixing for $10 \mathrm{~min}$, the melted samples were poured onto a glass plate for solidification and the solid samples were then scanned by DSC.

DSC scans were carried out on a heat-flux DSC, a model 822 $2^{\mathrm{e}}$ (Mettler Toledo, Schwerzenbach, Switzerland) instrument with a liquid nitrogen cooling system (Dewar vessel) and STAR ${ }^{\mathrm{e}}$ software. Samples of approximately $5 \mathrm{mg}$ were accurately weighed $( \pm 0.01 \mathrm{mg})$ and encapsulated in $40 \mathrm{~mL}$ flat-bottomed aluminum pans with crimped-on lids. Scans over a range of 10 to $280^{\circ} \mathrm{C}$ were obtained at a scanning speed of $5^{\circ} \mathrm{C} / \mathrm{min}$ under nitrogen stream at a flux rate of $80 \mathrm{~mL} / \mathrm{min}$. Each analysis was run in triplicate.

Indium (In) and zinc (Zn) standards were used to calibrate the DSC cell. Reference values for onset temperature and heat flow were as follows: $156.6^{\circ} \mathrm{C}$ and $28.45 \mathrm{~J} / \mathrm{g}(\mathrm{In}) ; 419.6^{\circ} \mathrm{C}$ and $107.5 \mathrm{~J} / \mathrm{g}(\mathrm{Zn})$, whereas the temperatures measured were: $156.6^{\circ} \mathrm{C}$ and $28.80 \mathrm{~J} / \mathrm{g}(\mathrm{In}) ; 420.1^{\circ} \mathrm{C}$ and $110.7 \mathrm{~J} / \mathrm{g}(\mathrm{Zn})$. The relative standard deviations (RSD) for the measured values varied over the range of 0.12 to $0.35 \%$.

The pharmacopoeial method was used for spectrophotometric determination of paracetamol in the suppositories (4). Samples of approximately 100 mg were accurately weighed $( \pm 0.1 \mathrm{mg})$ and transferred into $100-\mathrm{mL}$ graduated flasks. Next, $20 \mathrm{~mL}$ of chloroform was added, the suspensions were shaken for $10 \mathrm{~min}$ and diluted up to $100 \mathrm{~mL}$ with methanol. After shaking, aliquots of the supernatants were filtered through MN 640d ashless filter circles, $11 \mathrm{~cm}$ in diameter (Macherey-Nagel, Duren, Germany). One-mL portions of the filtrate were transferred into $100-\mathrm{mL}$ graduated flasks, $0.5 \mathrm{~mL}$ of $10 \% \mathrm{HCl}$ was added and diluted up to $100 \mathrm{~mL}$ with methanol. Drug content was determined at $249.5 \mathrm{~nm}$ on a UV1202 spectrophotometer (Shimadzu, Duisburg, Germany). Methanol was used as the reference liquid. The standard drug solutions obeyed Beer's law over the range of 0.8 to $1.2 \mathrm{mg} / 100 \mathrm{~mL}$ and the calibration equation was $\mathrm{y}=0.7898 \mathrm{x}+0.0959, \mathrm{r}=$ $0.9998, R^{2}=0.9996$. Each analysis was run in triplicate.

\section{RESULTS AND DISCUSSION}

To develop a simple, specific and accurate method for the determination of paracetamol in rectal preparations based on the measurement of its heat of fusion $\left(\Delta \mathrm{H}_{\mathrm{f}}\right)$, nineteen suppositories containing paracetamol and commonly available in Polish pharmacies were chosen. Suppositories are solid, single-dosage preparations with at least one active ingredient dispersed or dissolved in a suitable sup- 
pository base that may be soluble or dispersible in water or may melt at body temperature (3). Various excipients are available for the suppository bases, such as hard fat, macrogols, cocoa butter, and various gelatinous mixtures. For this reason, the study was also extended over the analysis of suppositories manufactured by various producers, but containing paracetamol at different doses. In this way, it was possible to estimate the impact of various suppository bases on the DSC determination of the drug in rectal formulations.

Inspection of the data given by manufacturers shows that the suppositories contained different suppository excipients despite containing the same active ingredient. For instance, Benuron preparations consisted of a solid fat as a suppository base, Calpol and Codipar suppositories were based on soybean lecithin and a neutral solid fat (a mixture of Witepsol H15 and Estram H15 suppository excipients), Efferalgan preparations included semi-synthetic triglycerides, whereas Paracetamol suppositories manufactured by Farmina and Hasco-Lek contained solid fats, Estram H15, and Witepsol S58, respectively.

\section{DSC of suppositories}

DSC scans of selected paracetamol suppositories containing the active ingredient at different doses and various suppository excipients are shown in Figures 1 and 2. All drug formulations and sup- pository bases exhibited broad, irregularly-shaped DSC endothermic peak over the range $30-43^{\circ} \mathrm{C}$, corresponding to the melting of the base. The broad shape is attributed to the fact that the suppository bases are a heterogeneous mixture of ingredients of similar properties, but with a polydisperse molecular mass distribution $(31,32)$. It can also be affirmed that an increase in paracetamol content over the range of 125 to $500 \mathrm{mg}$ in the rectal dosage form does not produce significant variations in the melting point of the suppository bases.

Well-defined endothermic DSC peaks at about $168-170^{\circ} \mathrm{C}$ due to the melting of paracetamol included in the suppositories are also observed in Figures 1 and 2 . The melting point of the drug concurs with the literature data, $168-172^{\circ} \mathrm{C}$ (4) and the values determined for the drug standard $\left(168.64^{\circ} \mathrm{C}\right.$ with the heat of transition of $183.99 \mathrm{~J} / \mathrm{g}$ ). This suggests that the melting point of paracetamol remains unaffected by the composition of the matrix (suppository excipients). Furthermore, as the concentration of paracetamol was increased from 125 to 500 $\mathrm{mg}$ in the suppositories under study, an increase in the area of DSC peak owing to the drug melting was clearly noticed. The Codipar (GSK Pharmaceuticals) and Paracetamol (Hasco-Lek) preparations prove the sole exceptions. Despite the fact that the suppositories contained 250 and $500 \mathrm{mg}$ of the drug (Figure $2 \mathrm{c}$ and $\mathrm{d}$ ), the areas of DSC peaks were comparable, because the formulation including

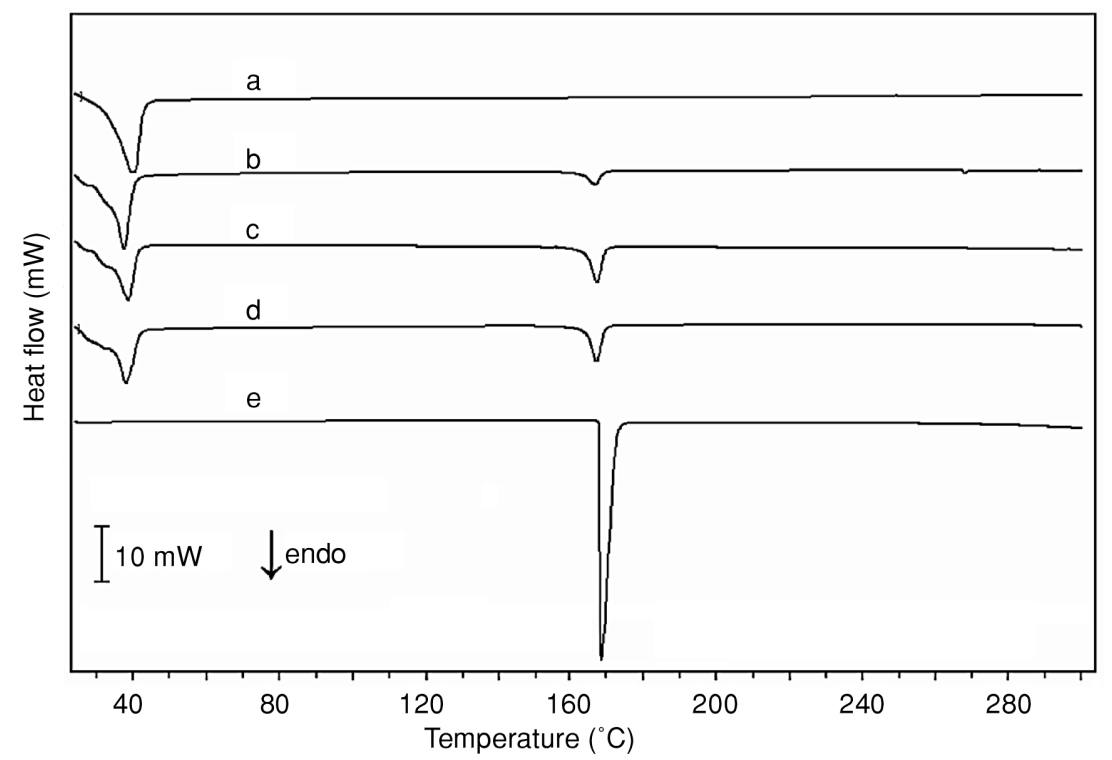

Figure 2. DSC scans for: (a) suppository base Witepsol S58, (e) paracetamol, and rectal formulations manufactured by Hasco-Lek containing the dose of drug: (b) $125 \mathrm{mg}$, (c) $250 \mathrm{mg}$, and (d) $500 \mathrm{mg}$ 
Table 2. Results of DSC determination of paracetamol in the commercially available suppositories $(\mathrm{n}=3)$.

\begin{tabular}{|c|c|c|c|c|c|}
\hline \multirow[t]{2}{*}{ Suppository } & \multicolumn{2}{|c|}{$\begin{array}{l}\text { Content of paracetamol } \\
\text { (mg/suppository) }\end{array}$} & \multirow{2}{*}{$\begin{array}{l}\text { RSD } \\
(\%)\end{array}$} & \multirow{2}{*}{$\begin{array}{c}\text { Relative } \\
\text { error } \\
(\%)\end{array}$} & \multirow{2}{*}{$\begin{array}{c}\text { Confidence interval } \\
\alpha=0.05 \\
\text { (mg/suppository) }\end{array}$} \\
\hline & Declared dose & Determined \pm SD & & & \\
\hline Paracetamol (Farmina) & 50 & $59.6 \pm 1.9$ & 3.20 & 19.27 & $54.9-64.4$ \\
\hline Calpol & 80 & $86.0 \pm 2.1$ & 2.49 & 7.50 & $80.7-91.3$ \\
\hline Efferalgan & 80 & $90.0 \pm 1.1$ & 1.25 & 12.50 & $87.2-92.8$ \\
\hline Paracetamol (Hasco-Lek) & 80 & $77.7 \pm 2.1$ & 2.64 & -2.92 & $72.6-82.8$ \\
\hline Benuron & 125 & $124.7 \pm 2.4$ & 1.90 & -0.24 & $118.8-130.6$ \\
\hline Calpol & 125 & $127.1 \pm 0.4$ & 0.34 & 1.68 & $126.0-128.2$ \\
\hline Paracetamol (Farmina) & 125 & $126.8 \pm 1.0$ & 0.82 & 1.44 & $124.2-129.4$ \\
\hline Paracetamol (Hasco-Lek) & 125 & $118.8 \pm 0.3$ & 0.27 & -4.99 & $118.0-119.6$ \\
\hline Efferalgan & 150 & $158.5 \pm 2.9$ & 1.86 & 5.69 & $151.2-165.9$ \\
\hline Benuron & 250 & $248.1 \pm 2.9$ & 1.18 & -0.77 & $240.8-255.3$ \\
\hline Codipar & 250 & $240.4 \pm 3.4$ & 1.41 & -3.84 & $232.0-248.8$ \\
\hline Paracetamol (Farmina) & 250 & $253.8 \pm 3.7$ & 1.45 & 1.53 & $244.7-263.0$ \\
\hline Paracetamol (Hasco-Lek) & 250 & $248.3 \pm 1.1$ & 0.47 & -4.69 & $235.5-241.1$ \\
\hline Efferalgan & 300 & $303.0 \pm 8.0$ & 2.65 & 1.00 & $283.1-322.9$ \\
\hline Benuron & 500 & $497.1 \pm 6.6$ & 1.32 & -0.59 & $480.8-513.3$ \\
\hline Codipar & 500 & $490.3 \pm 3.6$ & 0.74 & -1.94 & $481.2-499.4$ \\
\hline Paracetamol (Farmina) & 500 & $507.1 \pm 2.9$ & 0.58 & 1.41 & $499.8-514.3$ \\
\hline Paracetamol (Hasco-Lek) & 500 & $487.8 \pm 15.7$ & 3.21 & -2.43 & $448.9-526.7$ \\
\hline Benuron & 1000 & $971.7 \pm 8.6$ & 0.89 & -2.83 & $950.3-993.1$ \\
\hline
\end{tabular}

$250 \mathrm{mg}$ of drug weighs circa $1 \mathrm{~g}$ while that including $500 \mathrm{mg}$ of drug weighs circa $2 \mathrm{~g}$. The approximately twofold larger base in the other dosage form meant that the content of paracetamol was comparable $(24.5 \%)$ in both rectal formulations.

\section{Calibration techniques}

The heat of fusion values for paracetamol were acquired from the series of DSC scans for the samples of suppository bases with drug standard addition at increasing concentrations. The correlation coefficients of the best-fit lines are 0.9994 for Estram H15 suppository base $(\mathrm{y}=1.71 \mathrm{x}-3.68, \mathrm{n}=$ 3 ), and 0.9988 for Witepsol S58 ( $y=1.71 x-11.79$, $\mathrm{n}=3$ ), indicating a linear correlation between the $\Delta \mathrm{H}_{\mathrm{f}}$ and the drug content (c). The high values of intercept (b) in both calibration equations $\left(\Delta \mathrm{H}_{\mathrm{f}}=\mathrm{ac}\right.$ + b) may be indicative either of a systematic error in measurement or of the fact that the heat of fusion values are below that of the DSC detection limit determined in the study. For this reason, at a content of $2.16 \%$ of paracetamol in the mixtures with Estram $\mathrm{H} 15$ and of $6.89 \%$ in those with Witepsol S58, drug fusion could not be detected. Potential interaction between paracetamol and excipients resulting in reduced drug crystallinity and lowered enthalpy of fusion can be found in the literature (33). These interactions are due to mutual miscibility and solubility of ingredients in the solid-state.

Owing to the high intercept values, the decision was taken to use the multiple standard addition method despite the fact that the calibration curve was adopted to quantify paracetamol in suppositories including a mixture of hydrogenated palm kernel oil and hydrogenated palm kernel stearin as a suppository base (34). The main advantage of this method is that the matrix of the sample under study remains unchanged, while the instrument response is measured for all of the samples after the standard has been added (35). The multiple standard addition method is accepted by the Polish Pharmacopoeia, e.g., it is described in a monograph on absorption atomic spectrometry (4). Therefore, the method is suitable for drug determination in the suppositories obtained from various producers where the matrices are complex or difficult to reproduce. For example, the matrices of suppositories consist of mixtures of mono-, di- and triglycerides as well as the adjuvants 


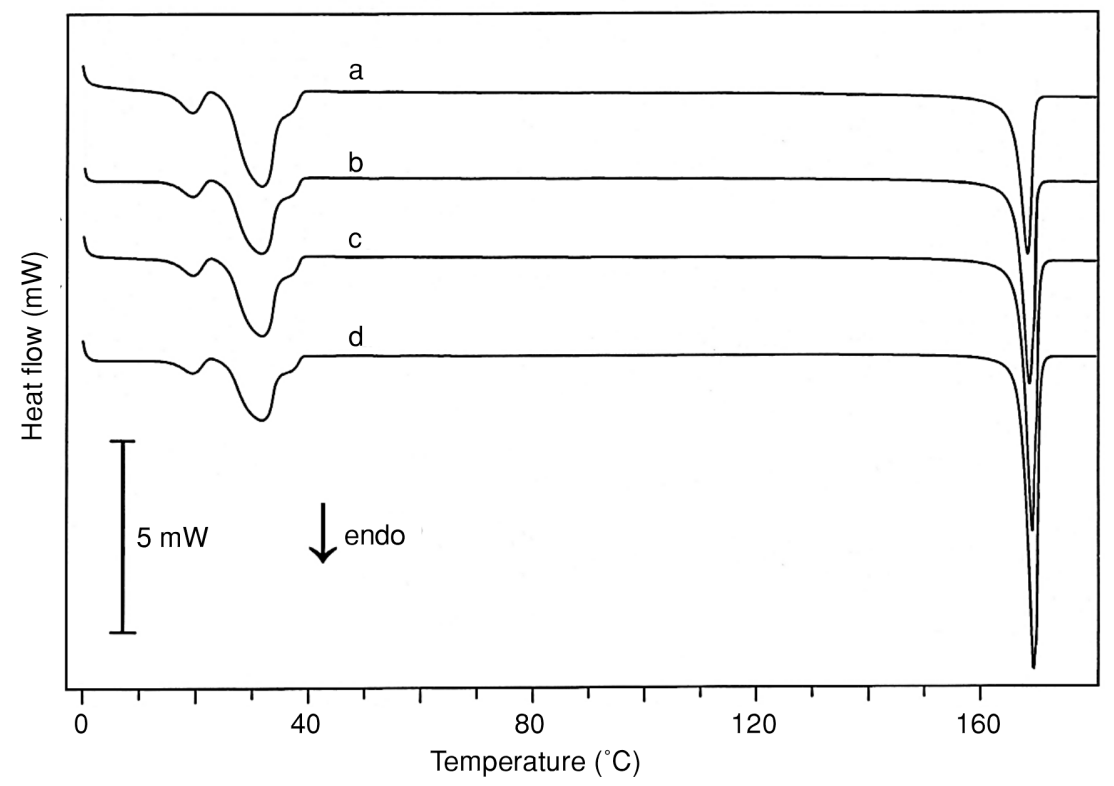

Figure 3. DSC scans for suppositories: (a) Paracetamol $250 \mathrm{mg}$ (Hasco-Lek) before and after addition of the adequate quantity of paracetamol as a drug standard: (b) $100 \mathrm{mg}$, (c) $200 \mathrm{mg}$, and (d) $300 \mathrm{mg}$

Table 3. Results of UV spectrophotometric determination of paracetamol in the commercially available suppositories $(\mathrm{n}=3)$.

\begin{tabular}{|c|c|c|c|c|c|}
\hline \multirow[t]{2}{*}{ Suppository } & \multicolumn{2}{|c|}{$\begin{array}{l}\text { Content of paracetamol } \\
\text { (mg/suppository) }\end{array}$} & \multirow{2}{*}{$\begin{array}{c}\mathrm{RSD} \\
(\%)\end{array}$} & \multirow{2}{*}{$\begin{array}{c}\text { Relative } \\
\text { error } \\
(\%)\end{array}$} & \multirow{2}{*}{$\begin{array}{c}\text { Confidence interval } \\
\alpha=0.05 \\
\text { (mg/suppository) }\end{array}$} \\
\hline & Declared dose & Determined \pm SD & & & \\
\hline Paracetamol (Farmina) & 50 & $54.1 \pm 0.1$ & 0.18 & 8.20 & $53.9-54.3$ \\
\hline Calpol & 80 & $79.1 \pm 1.1$ & 1.44 & -1.17 & $76.2-81.9$ \\
\hline Efferalgan & 80 & $80.3 \pm 0.5$ & 0.64 & 0.42 & $79.1-81.6$ \\
\hline Paracetamol (Hasco) & 80 & $82.1 \pm 0.8$ & 0.91 & 2.67 & $80.3-84.0$ \\
\hline Benuron & 125 & $118.3 \pm 0.6$ & 0.52 & -5.33 & $116.8-119.9$ \\
\hline Calpol & 125 & $126.5 \pm 1.2$ & 0.95 & 1.21 & $123.5-129.5$ \\
\hline Paracetamol (Farmina) & 125 & $132.0 \pm 1.0$ & 0.78 & 5.59 & $129.4-134.6$ \\
\hline Paracetamol (Hasco) & 125 & $127.0 \pm 0.8$ & 0.62 & 1.57 & $125.0-128.9$ \\
\hline Efferalgan & 150 & $151.0 \pm 2.3$ & 1.49 & 0.67 & $145.4-156.6$ \\
\hline Benuron & 250 & $242.0 \pm 1.4$ & 0.58 & -3.20 & $238.5-245.5$ \\
\hline Codipar & 250 & $244.8 \pm 1.6$ & 0.66 & -2.08 & $240.8-248.8$ \\
\hline Paracetamol (Farmina) & 250 & $262.4 \pm 4.0$ & 1.52 & 4.95 & $252.5-272.3$ \\
\hline Paracetamol (Hasco) & 250 & $255.2 \pm 4.1$ & 1.62 & 6.96 & $244.9-265.4$ \\
\hline Efferalgan & 300 & $296.0 \pm 4.1$ & 1.37 & -1.34 & $285.9-306.1$ \\
\hline Benuron & 500 & $497.3 \pm 3.9$ & 0.78 & -0.55 & $487.6-506.9$ \\
\hline Codipar & 500 & $479.0 \pm 5.9$ & 1.19 & -0.60 & $482.3-511.8$ \\
\hline Paracetamol (Farmina) & 500 & $535.4 \pm 7.4$ & 1.38 & 7.08 & $523.8-547.1$ \\
\hline Paracetamol (Hasco) & 500 & $508.1 \pm 4.8$ & 0.94 & 1.61 & $496.3-519.9$ \\
\hline Benuron & 1000 & $1006.3 \pm 8.8$ & 0.88 & 0.63 & $984.4-1028.2$ \\
\hline
\end{tabular}



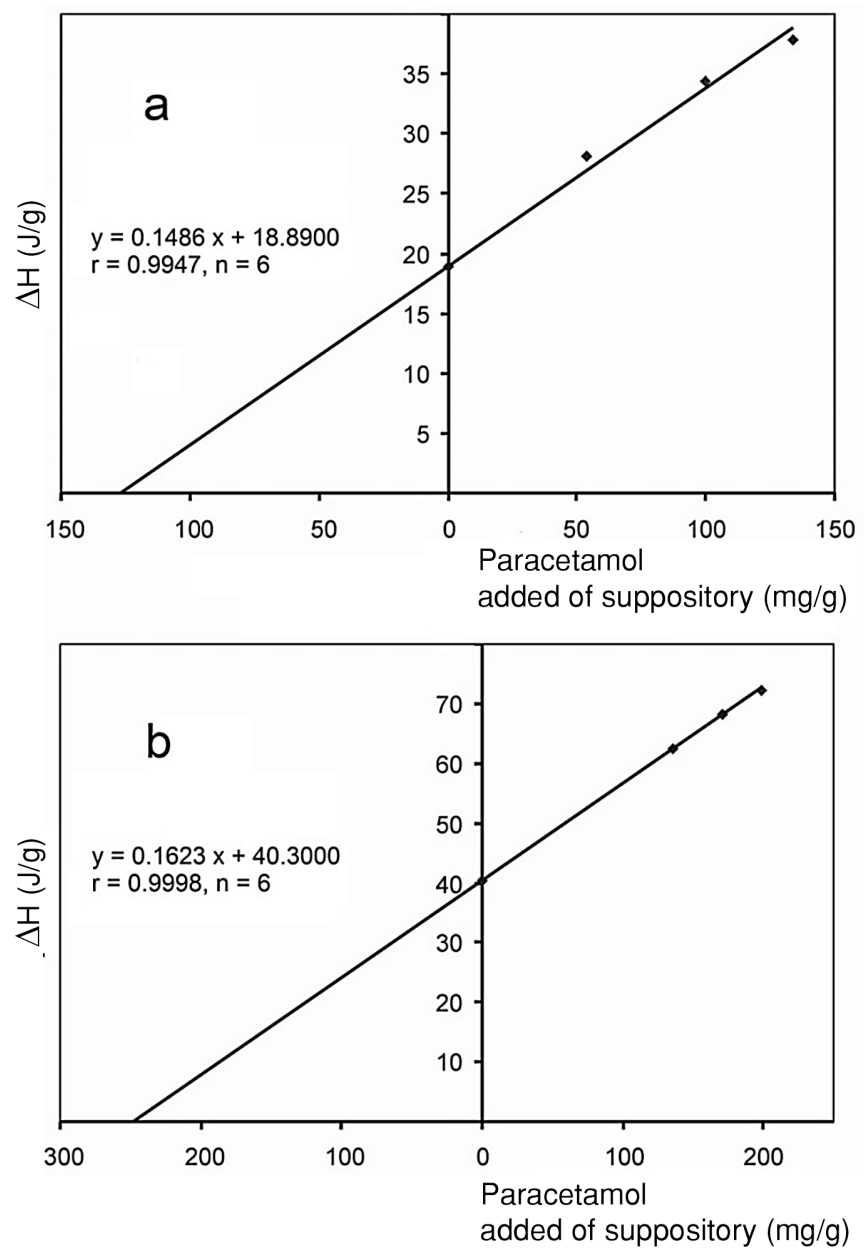

Figure 4. Plot for the multiple standard addition methods in the case of suppositories: (a) Calpol 125 mg (GSK Pharmaceuticals), (b) Paracetamol $250 \mathrm{mg}$ (Hasco-Lek)

(surfactants, polymers, waxes), which are used to improve the release and adsorption characteristics of the drug (32). The drugs and adjuvants can form eutectic mixtures, solid solutions or complexes with lipophilic excipients, thus modifying the melting behavior of a drug. For this reason, the use of the multiple standard addition method for the determination of paracetamol in the suppositories is justified.

The general idea of application of the multiple standard addition method is to monitor change in instrument response after the addition of increasing quantities of the analyte to portions of the sample (35). Sample portions are all made up to the same volume (to the same mass for solid samples) after the standard has been added. The total concentration of the analyte is a combination of the unknown and the standard, and the total concentration varies linearly. If the signal response is linear in this concentration range, a plot is generated for the determination of the unknown concentration of the analyte in the sample under study. The point at zero concentration added is the reading of the unknown, the remaining points are readings after the addition of increasing quantities of the standard. The absolute value of the $x$-intercept is the concentration of the analyte in the analyzed sample.

The quantities of paracetamol as the drug standard added to the suppositories in relation to the declared drug dose in the formulations are compiled in Table 1, whereas the DSC scans for the Paracetamol $250 \mathrm{mg}$ suppositories alone and after addition of the drug standard are shown in Figure 3. The heat of fusion obtained from the DSC scans for the samples before and after addition of paracetamol was plotted with the concentration of the standard added on the $x$-axis and the heat of fusion on the $y$-axis. This is graphically presented in 
Figure 4 for selected commercial suppositories at different drug doses. The concentration of paracetamol added is expressed in milligrams per gram of the sample while the heat of fusion is given in joules per gram of sample. Taking into account the linear regression equation, $\Delta \mathrm{H}_{\mathrm{f}}=\mathrm{ac}+\mathrm{b}$, the unknown concentration (c) of paracetamol in the suppository at $\mathrm{y}=0$ ( $\mathrm{y}$ being the instrument response) was calculated according to the formula $\mathrm{c}=\mathrm{b} / \mathrm{a}$, where $\mathrm{b}$ is the intercept and $a$ is the slope of the regression line.

\section{Comparison of the results}

The results of the study performed using DSC are listed in Table 2. The values obtained based on the manufacturer's information are shown as the "declared dose", those denoted as "determined" were calculated using DSC scans and the multiple standard addition method. The data obtained suggest that the principal factor affecting the DSC determination of paracetamol is its content in the rectal formulations, i.e., lower concentrations of the drug, lower accuracy, and precision of the measurements.

Statistical evaluation indicates that these results are on the whole accurate. Except for one suppository formulation with the lowest drug dose (only $50 \mathrm{mg}$ ), the relative error of the determination using DSC varies within the range of 0.24-12.50\%, whereas for the majority of determinations it is lower than $5.0 \%$. The results also allow DSC to be characterized as a precise method. Particular determinations are reproducible to a high degree. The RSD values for the majority of DSC determinations are lower than $1.5 \%$. Except for one suppository formulation with the lowest drug dose $(50 \mathrm{mg})$, the RSD values vary over the range of 0.27 to $2.64 \%$.

The results of the active ingredient determination in the same suppositories using UV spectrophotometry are compiled in Table 3. When comparing the two techniques, DSC and UV, it can be concluded that the results obtained using UV spectrophotometry are closer to the declared dose than those obtained by DSC. However, the results obtained using DSC are satisfactory, as the method used to perform the measurements using this technique was quite simple and required no preliminary preparation of the sample for analysis.

\section{CONCLUSIONS}

This study of commercially available suppositories has shown that a well-defined endothermic DSC peak due to the melting of paracetamol can be successfully used for the determination of the drug in for- mulations intended for rectal use. The method employed to perform measurements using this technique is simple and does not require tedious preliminary sample preparation. The multiple standard addition method ensures more effective determinations with clear precision and accuracy. Both, DSC technique and multiple standard addition method are accepted by the Polish Pharmacopoeia. The results also suggest that the principal factor affecting the DSC determination of drug is its content in rectal preparations, i.e., lower concentrations of the drug, lower precision and accuracy of the measurements. Moreover, the results are compatible with the data obtained for the same preparations using UV spectrophotometry (the pharmacopoeial method) as a reference.

\section{REFERENCES}

1. Bennett P.N., Brown M.J.: Clinical Pharmacology, $10^{\text {th }}$ edn., Churchill Livingstone, Elsevier, Edinburgh 2008.

2. Jóźwiak-Bębenista J., Nowak J.Z.: Acta Pol. Pharm. 71, 11 (2014).

3. European Pharmacopoeia $5^{\text {th }}$ edn., Council of Europe, Strasbourg (2005).

4. Polish Pharmacopoeia $8^{\text {th }}$ edn., Vol. 1, Ministry of Health, Warsaw (2008).

5. Adeyeye M.Ch., Brittain H.G. Eds.: Preformulation in Solid Dosage Form Development, Informa Healthcare, New York 2008.

6. Craig D.Q.M., Reading M. Eds.: Thermal Analysis of Pharmaceuticals, CRC Press, Boca Raton 2007.

7. Saunders M., Thermal analysis of pharmaceuticals, in Principles and Applications of Thermal Analysis. Gabbott P. Ed., Blackwell Publishing Ltd, Oxford 2008.

8. Regdon G.: The role of thermal investigations in drug formulations, in Thermal Analysis in Medical Application. Lorinczy D. Ed., Akademiai Kiado, Budapest 2011.

9. Mazurek-Wądołkowska E., Winnicka K., Czajkowska-Kośnik A., Czyżewska U., Miltyk W.: Acta Pol. Pharm. 70, 787 (2013).

10. Chadha R., Bhandari S.: J. Pharm. Biomed. Anal. 87, 82 (2014).

11. Rojek B., Suchacz B., Wesolowski M.: Thermochim. Acta 659, 222 (2018).

12. Klimova K., Leitner J.: Thermochim. Acta 550, 59 (2012).

13. Dichi E., Sghaier M., Guiblin N.: J. Therm. Anal. Calorim. 131, 2141 (2018).

14. Giordano F., Novak C., Moyano J.R.: Thermochim. Acta 380, 123 (2001). 
15. Maeno Y., Fukami T., Kawahata M., Yamaguchi K., Tagami T. et al.: Int. J. Pharm. 473, 179 (2014).

16. Saganowska P., Wesolowski. M.: J. Therm. Anal. Calorim. 133, 785 (2018).

17. Saunders M., Podluii K., Shergill S., Buckton G., Royall P.: Int. J. Pharm. 274, 35 (2004).

18. Planinsek O., Zadnik J., Kunaver M., Srcic S., Godec A.: J. Pharm. Sci. 99, 1968 (2010).

19. Gaisford S., Buanz A.B.M., Jethwa N.: J. Pharm. Biomed. Anal. 53, 366 (2010).

20. Haleem R.M., Salem M.Y., Fatahallah F.A., Abdelfattah L.E.: Saudi Pharm. J. 23, 463 (2015).

21. Siddiqui M.R., AlOthman Z.A., Rahman N.: Arab. J. Chem. 10, S1409 (2017).

22. Kataoka H.: Cur. Pharm. Anal. 1, 65 (2005).

23. Singh I., Juneja P., Kaur B., Kumar P.: ISRN Anal. Chem. (2013), 13 pages, doi:10.1155/ 2013/795178.

24. Espinosa Bosch M., Ruiz Sánchez A.J., Sánchez Rojas F., Bosch Ojeda C.: J. Pharm. Biomed. Anal. 42, 291 (2006).
25. Hoang V.D., Nhung N.P., Aboul-Enein H.Y.: Cur. Pharm. Anal. 9, 261 (2013).

26. Suchacz B., Wesolowski M.: Anal. Methods 8, 3307 (2016).

27. Wang G., Zhu J., Wu W., Zhang W.: Cur. Pharm. Anal. 14, 355 (2018).

28. Wesolowski M.: Thermochim. Acta 209, 223 (1992)

29. Talik P., Żuromska-Witek B., Hubicka U., Krzek J.: Acta Pol. Pharm. 74, 1049 (2017).

30. Mota F.L., Carneiro A.P., Queimada A.J., Pinho S.P., Macedo E.A.: Eur. J. Pharm. Sci. 37, 499 (2009).

31. Pryce-Jones R.H., Eccleston G.M., Abu-Bakar B.B.: Int. J. Pharm. 86, 231 (1992).

32. Margarit M.V., Caballero J.D.: Eur. J. Pharm. Sci. 19, 123 (2003).

33. Leyk E., Wesolowski M.: Front. Pharmacol. 10, 14 (2019).

34. Noordin M.I., Chung L.Y.: Drug Dev. Ind. Pharm. 30, 925 (2004).

35. Harris, D.C.: Quantitative Chemical Analysis, $8^{\text {th }}$ edn., Freeman \& Co., New York 2010.

Received: 26.09. 2018 